R. J. Cohen and W. T. Sullivan, III, eds.

\title{
Work for the Reduction of Light Pollution in Turkey
}

\author{
Z. Aslan \\ TÜBITAK National Observatory and Akdeniz Üniversitesi, Antalya, \\ Turkey
}

\begin{abstract}
In recent years Turkey has been losing the beauty of its night sky at a fast rate. The amount of outdoor lighting is increasing every day. University observatories at Ankara and İzmir are already irreversibly affected by light pollution. In this paper, work against light pollution in Turkey is outlined.
\end{abstract}

\section{Introduction}

The amount of outdoor lighting and, as a result, light pollution in Turkey is increasing at an incredibly fast rate in recent years. The university observatories at Ankara and Izmir are already irreversibly affected. The rate of light pollution is highest along the Mediterranean coast due to increased investments in tourism. Holiday villages and chains of new hotels are using decorative outdoor lighting. The sky brightness over Antalya increased from almost the level of natural background in 1986 to $23 \%$ higher in 1999 as seen from a distance of $30 \mathrm{~km}$ in a direction of 25 degrees altitude over the city. We have reason to believe that if the vertical light from the Antalya Riveria is controlled, the artificial sky glow could be cut down considerably. There are good and still dark potential observatory sites along the Mediterranean coast in the Taurus Mountains, which are now under threat. These include the recently established National Observatory, for which the site was selected in 1986 and construction began in 1992 .

\section{Work against Light Pollution}

Through the initiative of TÜBITAK (Scientific and Technical Research Council of Turkey) National Observatory, we have started a campaign against light pollution in Turkey. We got help from astronomers and from members of astronomy clubs in different cities in photographing examples of energy waste, poor lighting quality and poor lighting designs and installations. These are for use in our reports to local authorities, the press, and in our talks on television and radio, with the aim of getting light pollution to receive national attention. In reports and talks to local and central government officials responsible for outdoor lighting, due emphasis on energy waste has been rewarding.

A National Committee has been formed under the coordination of TÜBİTAK with members from the National Energy Conservation Centre (Ministry of En- 
ergy and Natural Resources), Highways Directorate, National Committee on Illumination and the Turkish Standards Institute. The committee has been working on a national awareness programme and on public education via the media, conferences, talks, information leaflets, etc. We emphasize energy waste, adverse effects on natural life, and the astronomical knowledge and culture we have inherited as a Mediterranean country, not to mention the value of the night sky as a "tool" for education. A sub-committee is studying local and national regulations on outdoor lighting, with a view to update these to include new standards. The Turkish Standards Institute is studying outdoor lighting and standards issued by other countries, in order to adopt national standards. The Committee is putting pressure on the central government to enact laws to curb light pollution, as well as on municipal governments to issue regulations to improve night-time visibility and to reduce urban sky glow. It is a slow and difficult process but we hope that the new standards and regulations will soon be available.

\section{Work for Potential Observatory Sites}

In order to promote the protection of potential observatory sites, a plan is being made to measure the artificial skyglow from regions in the Taurus Mountains along the Mediterranean coast using a portable Celestron- 8 telescope equipped with a photometer. We will then try to persuade the central and local municipal governments to adopt regulations to protect the sites. 